\title{
ESTUDO COMPARATIVO ENTRE OS MÉTODOS DE CÁLCULO DE PULMÃO UTILIZANDO A LÓGICA FUZZY E MÉTODO DOS CINQUENTA POR CENTO
}

\author{
Study comparing the buffer calculation methods using the \\ Fuzzy Logic and Fifty Percent Method
}

\author{
Zhou Guan Chen ${ }^{1}$, Tatiana Gondim do Amaral ${ }^{2}$, Vitor Hugo Martins e Resende ${ }^{3}$, \\ Marcos Antônio de Sousa ${ }^{4}$
}

Recebido em 09 de setembro de 2016; recebido para revisão em 02 de março de 2017; aceito em 04 de abril de 2016; disponivel on-line em 16 de maio de 2017.

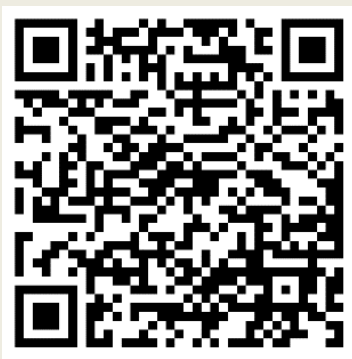

PALAVRAS CHAVE:

Fachadas ventiladas; Revestimento de porcelanato;

Desempenho das edificações; Simulação computacional.

\section{KEYWORDS:}

Ventilated façades; Porcelain tiles covering; Building performance; Computer simulation.

RESUMO: Levantamentos realizados apontam atrasos em obras gerando insatisfações aos clientes, motivando processos judiciais sobre as construtoras além de custos indiretos adicionais no projeto, levando a prejuízos ao mesmo. Mediante o exposto são necessárias ferramentas mais eficazes para o controle de prazo de obra. Assim, o trabalho visa aplicar e avaliar o método da corrente crítica no planejamento e controle físico de obras, calculando o pulmão do projeto utilizando duas técnicas distintas: Métodos Número Fuzzy trapezoidal (TrFN) e cinquenta por cento. Portanto, realizou-se um estudo de caso de um empreendimento mixed use em Goiânia e um acompanhamento dos serviços estruturais de uma junta, que estão presentes na corrente crítica do projeto. Assim, ao avaliar e comparar os pulmões resultantes, durações calculadas e reais do projeto, se conclui que o Método TrFN é o que mais se aproxima à duração real, pois consulta especialistas; e, mais se integra à equipe, aumentando a aplicabilidade do planejamento, pois os executores do projeto participam na elaboração do mesmo. Já o Método dos Cinquenta por Cento é mais fácil de ser calculado, com a definição mais prática do pulmão resultando um planejamento mais rápido. Baseando-se nesses cálculos, a principal contribuição do trabalho é comparar os resultados de cada técnica quanto à sua agilidade de aplicação, precisão em relação ao real e aplicabilidade em obra.

ABSTRACT: Conducted surveys indicate delays in projects that impact clients, allowing lawsuits over Construction Company and overhead costs of the project, enabling the economic impracticability of it. Through the above are needed more effective tools for term control of the project. Therefore, the work objective is to implement and evaluate the method of the critical chain in the planning and physical control of the project by calculating the project buffer using two different techniques: Trapezoidal Fuzzy Number (TrFN) and Fifty percent Method. Therefore, there was a case study of a mixed use building in Goiânia and monitoring of structural services of a joint, which are present in the project critical chain. Thus, to evaluate and compare the resulting buffer, calculated duration and really happened duration, it is concluded that the TrFN method comes closest to real time as it consults experts; and more integrates the team, increasing the applicability of planning, because the project performers are involved in preparing it. Now the fifty percent method is easier to be calculated with faster definition of the buffer and planning. Based on this calculus, the main contribution of this work is to compare the results of each technique in: application agility, application accuracy, applicability during construction.

* Contato com os autores:

${ }^{1}$ e-mail: zhouzgc@gmail.com (Z. G. Chen)

Graduando em Engenharia Civil, Escola de Engenharia Civil e Ambiental da Universidade Federal de Goiás - UFG.

2e-mail: tatiana_amaral@hotmail.com (T. G. do Amaral)

Enga. Civil, Doutora, Professora da Escola de Engenharia Civil e Ambiental, Universidade Federal de Goiás - UFG.

${ }^{3}$ e-mail:vhmr@hotmail.com (V.H. M. e Resende)

Tecnólogo em Eletromecânica, Professor, Mestre, Pontifícia Universidade Católica de Goiás - PUC-Goiás.

${ }^{4}$ e-mail: mas@pucgoias.edu.br (M. A. de Sousa)

Eng. Elétrico, Professor, Doutor da Pontifícia Universidade Católica de Goiás - PUC-Goiás. 


\section{INTRODUÇÃO}

Apesar da diversidade das ferramentas computacionais e de gestão existentes, os atrasos ainda são problemas frequentes na construção civil, em escala nacional e global. Em acréscimo, o gerenciamento de projetos nesse setor, cujo objetivo é o cumprimento dos prazos, não é eficaz (Resende, 2015).

De Fillippi e Melhado (2015) levantaram os atrasos de 32 empreendimentos na região metropolitana de São Paulo, em que a média de descumprimento no prazo foi de 4,7 meses, e dentre eles, duas obras atrasaram 10 meses. Pereira (2012) estudou 31 empresas em Santa Catarina, consultou 82 clientes e concluiu que $53,8 \%$ dos empreendimentos foram entregues fora do prazo estipulado. Silva et. al. (2011) acompanharam cinco clientes que buscavam apartamentos na planta, na cidade do Rio de Janeiro, e constatou que todos os clientes sofreram consequências de atrasos da obra.

Cabrita (2008) realizou um levantamento de atrasos na construção civil que abrange os continentes asiático, europeu, americano, africano, que ocorreram no período de 1971 a 2006. O estudo foi feito a partir de 19 publicações de 13 países diferentes, e se percebeu que as causas mais recorrentes dos atrasos estavam ligadas ao planejamento e controle de obras.

Atrasos na execução de empreendimentos geram transtornos aos clientes e empresa construtora. Os transtornos psicológicos com consequências financeiras dos clientes resultam em processos judiciais às empresas construtoras. Para a obra, os atrasos aumentam os custos indiretos do orçamento previsto, possibilitando o surgimento de prejuízos para a empresa construtora.

Visto que o não cumprimento do prazo é recorrente na construção civil em escala nacional e mundial, e suas consequências, tornam-se necessárias ferramentas de planejamento e controle de obras mais eficazes.

Em 1997, Goldratt publica o livro Corrente Crítica, que aplica a Teoria das Restrições no gerenciamento de projetos. A metodologia da corrente crítica é uma técnica de gerenciamento de projetos que administra prazos, atividades e recursos. Esse método organiza as atividades de forma que elas sigam restrições de tempo e recursos, criando uma sequência de atividades críticas, que não podem sofrer atrasos, pois elas interferem diretamente na data final do projeto (Goldratt, 1997).

Para evitar os atrasos da sequência crítica, Goldratt (1997) atribui a cada atividade um pulmão, um tempo reservado para imprevistos. A junção dos pulmões das atividades da corrente crítica chama-se pulmão do projeto. $O$ cálculo correto do pulmão do projeto, para adequar corretamente às incertezas de cada atividade, possibilita o resguardo de imprevistos, dando ao gerenciador maiores chances de contornar as situações problemáticas e finalizar o projeto dentro do prazo.

Goldratt (1997) utiliza o Método dos Cinquenta por Cento para o cálculo do pulmão de seu projeto. Esse método de cálculo, apesar de suas vantagens, é criticado por tornar o planejamento mais vulnerável às incertezas (Quelhas e Barcaui, 2005). Em 2007, Long e Ohsato trouxeram ideias da lógica Fuzzy para o cálculo de pulmão, quantificando as incertezas inerentes à execução do projeto, sugerindo uma alternativa ao método de 1997.

\section{OBJETIVOS}

\subsection{OBJETIVO GERAL}

O objetivo desta pesquisa é aplicar e avaliar a corrente crítica como método de planejamento e controle físico de obras, comparando dois métodos de cálculo de pulmão, número Fuzzy trapezoidal (TrFN) e pelo método de cinquenta por cento. Além de analisar qual dos dois métodos de cálculo promove maior integração da equipe; é mais ágil, possibilitando a entrega mais rápida do planejamento de longo prazo da obra e é mais assertivo em relação a realidade da obra.

\section{REVISÃO BIBLIOGRÁFICA}

\subsection{MÉTODOS DE CÁLCULO}

Long e Ohsato apresentaram em 2007 o método de cálculo Número Fuzzy Trapezoidal 
( $T r F N)$, que consiste em coletar e manipular dados de especialistas, para concluir a duração para determinada atividade e o pulmão do projeto. Goldratt publicou em 1997 o método de cálculo de pulmão dos cinquenta por cento. As durações são determinadas pelo próprio planejador, e o pulmão é calculado através da manipulação dessas durações.

\subsubsection{Número Fuzzy Trapezoidal (TrFN)}

Long e Ohsato (2007) utilizam a lógica Fuzzy para o cálculo do pulmão de seu projeto, com base em julgamentos de especialistas. $O$ método proposto calcula o pulmão através da raiz quadrada do somatório do quadrado dos tempos de segurança de cada atividade da corrente crítica, conforme Equação 1.

$$
P B=\sqrt{\sum s t^{2}}
$$

Em que:

PB = Pulmão do projeto (Project Buffer) (dias); st $=$ Tempo de segurança (Safety Time) (dias).

O tempo de segurança de cada atividade é dado através da diferença de dois valores obtidos com base nas informações dos especialistas, conforme Equação 2.

$$
s t=t h-t^{*} \quad \text { Eq. [2] }
$$

Em que:

$\mathbf{t}^{*}=$ Duração determinística adequada para atividade (Suitable Deterministic Duration) (dias); th = Duração com alto índice de concordância (High Agreement Duration) (dias).
A duração th é obtida através do TrFN, método que manipula quatro informações de tempo dados por especialistas ( $a, b, c, d)$, para estimar incertezas na duração de cada atividade (Figura 1).

De acordo com o método trapezoidal, quaisquer valores menores que "a" ou maiores que "d" possuem um grau de pertinência igual à zero. Entre os valores de "a" e "b", o grau de pertinência cresce linearmente de zero a um. No intervalo "b" e "c", é constante e igual a um. Já entre "c" e "d", decresce linearmente de um a zero. Assim, a função de pertinência do método se dá pela Equação 3.

$$
\mu(t)=\left\{\begin{array}{cc}
\frac{\mathrm{t}-\mathrm{a}}{\mathrm{b}-\mathrm{a}}, & \text { para } t \in[\mathrm{a}, \mathrm{b}] \\
1, & \text { para } t \in[\mathrm{b}, \mathrm{c}] \\
\frac{\mathrm{d}-\mathrm{t}}{\mathrm{d}-\mathrm{c}}, & \text { para } t \in[\mathrm{c}, \mathrm{d}] \\
0, & \text { para } t \notin[\mathrm{a}, \mathrm{d}]
\end{array}\right.
$$

Em que:

$\boldsymbol{\mu}(\mathbf{t})=$ Função de pertinência, variando com o tempo (Membership Function);

$\mathbf{a}, \mathbf{b}, \mathbf{c}, \mathbf{d}=$ Dados obtidos através dos especialistas.

Em seguida, determina-se a geometria de um retângulo através da área da Equação 4.

$$
\alpha(t)=1
$$

\section{Em que:}

$\alpha(t)=$ Função do retângulo;

$0 \leq \mathbf{t} \leq$ th

a $<$ th $<$ d

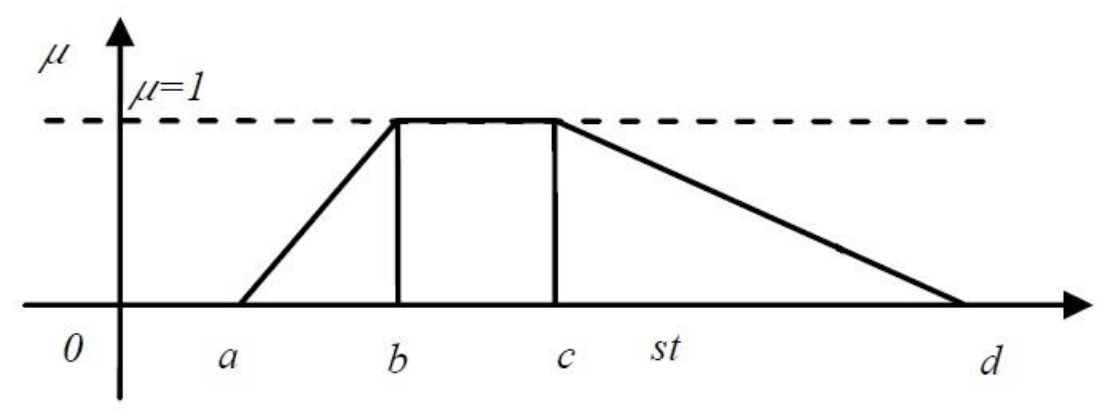

FIGURA 1: Disposição gráfica dos valores a, b, c, d.

FONTE: do autor (2016). 
Dessa forma, define-se Área (A) como a área do trapézio e Área (B) como a área do retângulo, obtidos através das integrais das Equações 3 e 4, respectivamente. A interseção entre Área $(A)$ e Área (B) se dá por Área $(A \cap B)$, conforme ilustrado na Figura 2.

O próximo item a ser definido é o índice de concordância Al, que traduz a confiança que se tem nos dados obtidos através dos especialistas, utilizados para formular a área do trapézio (Figura 2). Considerando a alta experiência dos mesmos, Al será um valor alto, próximo de um $(A \mathrm{I}=0,9)$. Matematicamente, $\mathrm{Al}$ é definido de acordo com a Equação 5.

$$
A I(A, B)=\frac{\text { Área }(A \cap B)}{\text { Área }(A)}
$$

Em que:

$\mathbf{A l}(\mathbf{A}, \mathbf{B})=$ Índice de concordância (Agreement Index); Área $(\boldsymbol{A} \cap \boldsymbol{B})=$ Área da interseção entre as áreas do trapézio e do retângulo;

Área $(\boldsymbol{A})$ = Área do trapézio.
Desenvolvendo a Equação 5, obtém-se a Equação 6.

A duração $t *$ também se forma a partir do arranjo (a, b, c, d). A duração determinística adequada $t^{*}$ situa-se entre os valores de maior possibilidade de se realizar, ou seja, que possuem graus de pertinência iguais a um, evidenciado na Equação 7.

$$
b \leq t^{*} \leq c
$$

Para o cálculo de $\mathrm{t}^{*}$ é utilizado um algoritmo genético padrão, obtendo uma solução ótima de duração. $O$ algoritmo é uma técnica iterativa, que procura resolver o problema de Planejamento do Projeto com Limitação de Recursos (RCPSP), que trabalha com variáveis de duração da atividade e tamanho da equipe para executá-la. Nesse estudo, utiliza-se um método de cálculo adaptado, detalhado na metodologia do trabalho.

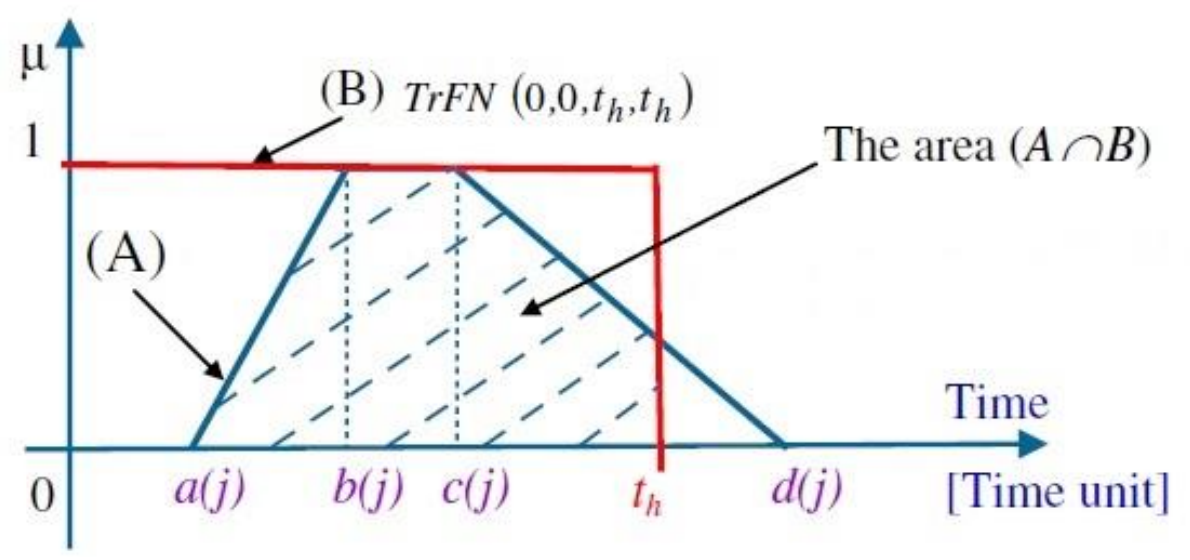

FIGURA 2: Gráfico evidenciando a área $A, B, A \cap B$.

FONTE: Long e Ohsato (2007).

$$
\left(\left((c-b+d-a) / 2-\left((d-t h)^{\wedge} 2 /(2 *(d-c))\right)\right) /(c-b+d-a)\right) / 2=0,9
$$




\subsubsection{Método dos Cinquenta por Cento}

Goldratt (1997) parte de três premissas ao introduzir a teoria da corrente crítica:

A primeira premissa explica que ao executar um planejamento, o planejador impõe uma margem de alta segurança, ao definir a duração das atividades. Essa margem alta é utilizada devido à dificuldade de previsão da duração, antes do projeto iniciar. É natural o planejador definir um prazo maior para a atividade, aumentando as chances da execução da mesma acontecer dentro do prazo estipulado por ele. Assim, Goldratt (1997) sugere reduzir a duração prevista da atividade pela metade, utilizando a outra metade como uma duração reserva.

O fato de reduzir a duração da atividade para cinquenta por cento do valor original se dá em função da distribuição normal. A curva gaussiana indica que a probabilidade de um evento de tempo da mediana ocorrer é de cinquenta por cento.

A segunda premissa diz que ao utilizar a multitarefa, um mesmo recurso executa diversas tarefas distintas, a duração de cada tarefa aumenta, além de acrescentar um atraso para a troca de tarefa, impactando no prazo estabelecido pelo planejamento. Assim, Goldratt (1997) sugere eliminar as multitarefas.

A terceira premissa explica como a interdependência entre as atividades geram atrasos, baseados em:

- Síndrome do estudante: É comum as pessoas deixarem para a última hora o início de suas atividades. Dessa forma, a redução no tempo de duração da atividade, reduz o atraso que o colaborador deixaria acontecer. Isso explica o motivo das durações reserva de cada atividade serem realocadas para o final do projeto, chamando-se pulmão do projeto.

- Lei de Parkinson: É normal as pessoas utilizarem todo o prazo disponível para realizar a atividade, mesmo quando elas conseguem finalizar mais cedo. Supondo que há duas atividades 1 e 2 e que comecem ao mesmo tempo. Se há um colaborador executando a atividade 1 , com prazo $x$, que precisa terminar seus serviços junto com a atividade 2 , com duração $2 x$, esse colaborador irá demorar mais que $\mathrm{x}$ para finalizar a atividade 1 . Dessa forma, Goldratt (1997) sugere que as atividades não se iniciem juntamente, mas que se alinhem seus términos. Assim, além de economizar recurso, se houver alterações de projeto, menos atividades terão sido iniciadas.

Goldratt (1997) calcula o pulmão de seu projeto por meio do método do cinquenta por cento. O autor manipula a duração de cada atividade de seu projeto, considerando cinquenta por cento dela como a nova duração da atividade e os outros cinquenta por cento como o tempo de segurança da atividade, de acordo com a primeira premissa do autor. Por meio disso, o método de cálculo do pulmão soma todas as durações de segurança das atividades que compõem a corrente crítica, deslocando-as para o final do projeto, de acordo com a terceira premissa. Ao fim, o autor considera cinquenta por cento dessa soma como o pulmão do projeto, baseando-se novamente na primeira premissa (Equação 8).

$$
P B=\frac{\sum t k}{2}
$$

Em que:

PB = Pulmão do projeto (Project Buffer);

$\mathbf{t k}=$ Tempo de segurança de cada atividade da corrente crítica (Safety Time).

Nesse método, as novas durações das atividades são apenas cinquenta por cento da duração total, e os outros cinquenta por cento participam do cálculo do pulmão do projeto. Nesse caso, o tempo reserva de todas as atividades serão alocadas para o final, somadas e dividas por dois em função delas pertencerem à corrente crítica do projeto, conforme ilustrado na Figura 3.

Considerando que o método de cálculo de pulmão de Goldratt (1997) baseia-se em probabilidade, e que cinquenta por cento das ocorrências terminarão antes do prazo e o restante finalizará depois do prazo, conclui-se que as oscilações serão recorrentes no consumo do pulmão. Além disso, padronizar o cálculo para quaisquer planejamentos torna o método mais suscetível às incertezas inerentes a cada projeto. 


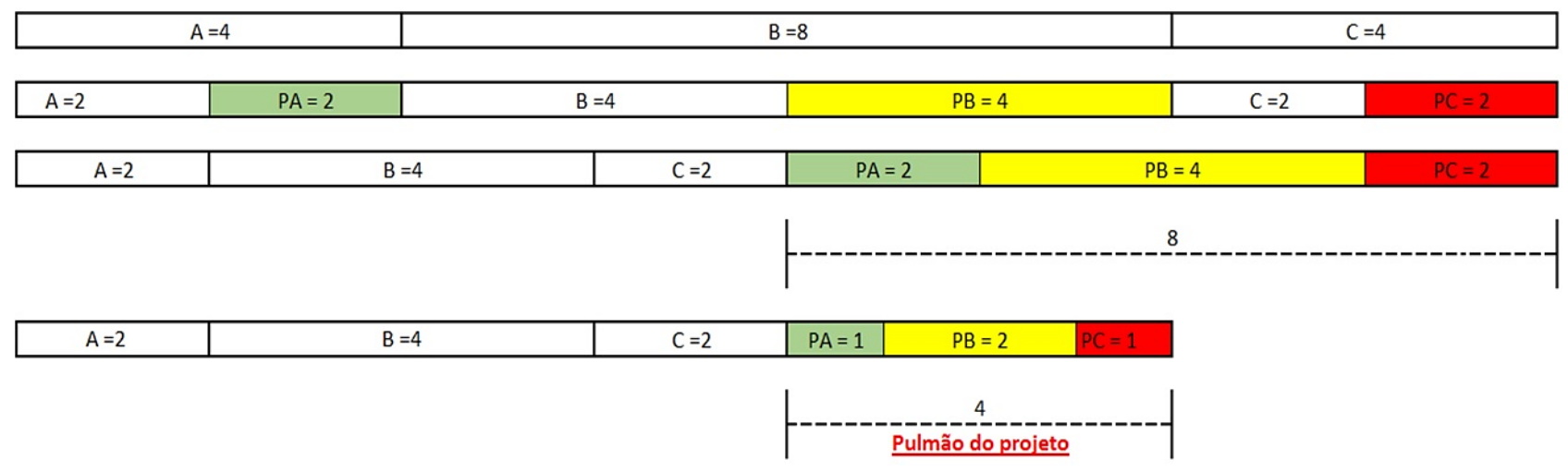

FIGURA 3: Desenho representativo do Método dos Cinquenta por Cento de cálculo de pulmão FONTE: Adaptado de Resende (2015).

\section{METODOLOGIA}

A metodologia da pesquisa se classifica como estudo de caso, em relação aos procedimentos técnicos; exploratória quanto ao objetivo; aplicada quanto à natureza; quantitativa em relação à abordagem.

\subsection{CRITÉRIOS PARA SELEÇÃO DA EMPRESA PARTICIPANTE}

Para aplicação dos métodos determinados pelos pesquisadores foram apontados requisitos para a seleção da empresa, dentre os quais se destacam:

Necessidade de a empresa possuir uma área ou um departamento, formalizado ou não, cujas atividades fossem voltadas para o planejamento e controle de obras.

- Necessidade de a empresa utilizar o software de gestão Projetos Ms Project com a função de criação de cronograma de obras tipo gráfico de Gantt.

- Possuir metas visando atender aos prazos estipulados no planejamento físico determinado previamente.

Possuir uma obra em andamento para a aplicação da corrente crítica.

Dentre os diversos tipos de programas de planejamento disponíveis, utilizou-se o MS Project em função do programa já ter sido estudado para fins de cálculo de pulmão da corrente crítica do projeto por Resende (2015) e por ser um software amplamente utilizado pelo setor.

\subsection{DEFINIÇÃO DAS ATIVIDADES PARA ACOMPANHAMENTO}

As atividades a serem acompanhadas foram definidas a partir do cronograma inicial da execução do empreendimento. Assim, inicialmente, o acompanhamento seria sob os seguintes serviços da junta A:

1) Montagem de fôrma dos pilares;

2) Montagem de armação dos pilares;

3) Concretagem dos pilares;

4) Desforma dos pilares;

5) Montagem de fôrma das vigas e laje;

6) Montagem de armação das vigas e laje;

7) Concretagem das vigas e laje;

8) Desforma das vigas e laje.

Durante a primeira visita à obra, ao conhecer a realidade da mesma e explicar as intenções do projeto de pesquisa ao engenheiro de produção, foi sugerida uma mudança pelo mesmo. Assim, o acompanhamento foi feito para as seguintes atividades:

1) Fôrma, armação e concretagem de pilares;

2) Escoramento e montagem de formas da laje e vigas;

3) Armação de laje e vigas;

4) Concretagem de laje e vigas.

A alteração justificou-se em decorrência dos serviços que subdividem o serviço de pilares possuírem duração curta, trazendo a estimativa dessas atividades para uma duração em horas, calculando um pulmão menor ainda, não possibilitando assim o consumo do pulmão. 
Outro tópico discutido foi o não acompanhamento da atividade de desforma. O serviço de desforma acontece em um ritmo paralelo ao caminho do serviço de estruturas, que é visto no caso de pilares. As fôrmas dos pilares são montadas, em seguida a armação é posicionada e por fim, a peça é concretada. No dia seguinte, a montagem de fôrma da laje e vigas é iniciada sob os pilares, sem a necessidade da atividade de desforma. Assim, essa atividade não impacta diretamente no prazo do serviço. Há apenas a necessidade de aguardar o tempo de cura do concreto do pilar e organizar pares de fôrmas para que não faltem nos pavimentos subsequentes.

\subsection{MÉTODO DE CÁLCULO DO NÚMERO FUZZY TRAPEZOIDAL (TrFN)}

A metodologia utilizada na obtenção do pulmão do projeto estudado foi baseada no método de Long e Ohsato (2007). Os mesmos procedimentos de cálculo foram feitos objetivando a duração do pulmão do projeto em estudo.

Algumas adaptações foram necessárias para o cálculo. Originalmente Long e Ohsato (2007) trabalham a variável $\mathrm{t}^{*}$ com base nos recursos disponíveis para a atividade. Além disso, esse valor sempre se encontra no intervalo entre " $b$ " e " $c$ ", intervalo cujo grau de pertinência é igual a um, pois ele é o valor de maior possibilidade de acontecer.

Assim, por não considerar os recursos na análise desse projeto, a duração determinística adequada $t^{*}$ é definida como a média aritmética entre os dois valores intermediários (" $b$ " $e$ " $c$ "). No momento do levantamento dos dados, foram questionados quatro especialistas diretamente envolvidas no processo executivo, sendo eles:

- 1 ㅇ Especialista: Engenheiro de produção (1),

- 2o Especialista: Mestre de obras (2),

- 3o Especialista: Encarregado de carpintaria (3),

- 4을 Especialista: Encarregado de armação (4).

A intenção era a coleta de opiniões dos colaboradores que executam o serviço (no caso, carpinteiro e armadores), substituindo um dos encarregados. Porém, ao mudar o acompanhamento dos serviços executados de acordo com a sugestão do engenheiro de produção, percebeu-se a necessidade de entrevistar especialistas que dominassem os prazos do processo executivo geral, constituído de fôrma, armação e concretagem, para que pudessem opinar certeiramente o prazo do serviço de pilares por exemplo. Dessa forma, optou-se por questionar um encarregado a mais que faça parte do processo executivo ao invés de um colaborador operacional.

De cada especialista, são coletadas duas opiniões para as determinadas atividades: os prazos, otimista (o) e pessimista (p). O índice "o" se refere às opiniões otimistas, e o " $p$ " às pessimistas. Os números que os acompanham se referem à fonte da informação, sendo 1 para engenheiro, 2 para o mestre, 3 para o encarregado de carpintaria, 4 para o encarregado de armação.

Dessa forma, obtêm-se três conjuntos de opiniões dos especialistas:

- tOTAl (o1, o2, o3, o4, p1, p2, p3, p4), composto por oito dados,

- PESSIMISTA (p1, p2, p3, p4), composto por quatro dados,

- OtIMista (01, 02, 03, 04), composto por quatro dados.

Os dados a, b, c, d são tratados antes de comporem a Equação 6:

- O item "a" é definido como o menor valor do conjunto TOTAL.

- O item "b" é definido como a média dos valores do conjunto OTIMISTA.

- O item "c" é definido como a média dos valores do conjunto PESSIMISTA.

- O item "d" é definido como o maior valor do conjunto TOTAL.

Os itens $a, b, c$ e d foram tratados dessa maneira para que sempre haja a possibilidade de se formar um trapézio no gráfico, permitindo a utilização do método de cálculo do número Fuzzy trapezoidal (TrFN) (Figura 2).

Para evitar que as respostas de todos os especialistas convergissem para um mesmo dado, retirando a incerteza e a possibilidade de cálculo do pulmão através da lógica Fuzzy, foi-se coletado dois dados de cada especialista. Assim, cada um deles fornece uma duração pessimista e otimista, tendo que variar o que seria uma resposta automática 
para eles, cedendo margem para o pensamento crítico de possíveis interferências.

Durante a pesquisa, percebeu-se que a duração real de todas as atividades é de sete dias trabalhados, diferente do que mostra ao somar-se a duração separada de cada atividade, resultando em 9,5 dias. Esse fato se dá em função da sobreposição das atividades no planejamento, conforme ilustrado na Figura 4, originado a partir de uma particularidade do projeto estudado. A laje em questão possui $680 \mathrm{~m}^{2}$, sendo possível mobilizar mais de uma equipe para executarem serviços diferentes.

Dessa forma, antes de uma atividade finalizar, outra pode ser iniciada, apesar de serem atividades predecessoras. Analisando a sequência de execução dos serviços, se percebe que essa sobreposição de atividades no caminho crítico é aparente.

Para exemplificar, na Figura 5 detalha-se a atividade de execução de pilares, percebendo que se executa o pilar P1, no tempo t1, o P2 em t2, o Pn em tn. Sendo a somatória dos tempos $t 1$ à tn igual ao tempo da atividade de pilar: 2,5 dias.

A montagem de cimbramento do local do pilar P1 não aguarda a finalização do pilar Pn para iniciar. Assim, ao agrupar as atividades de pilar P1 à Pn, em uma única atividade chamada execução de pilares, esse efeito de sobreposição aparece. Segue o mesmo raciocínio para as outras atividades. Dessa forma, para efeito de cálculo e estudo, considera-se a duração das atividades como 9,5 dias, e não 7 dias como é na prática, em decorrência de uma particularidade do projeto: o tamanho da laje, viabilizando a mobilização de mais de uma equipe (Figura 6).

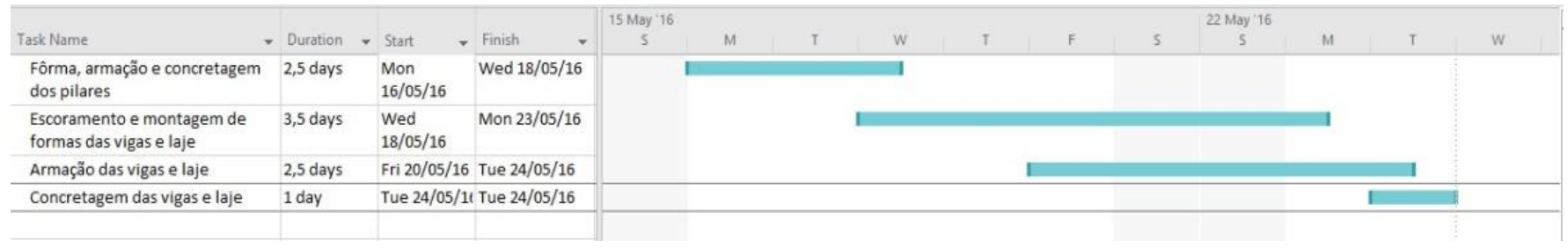

FIGURA 4: Aparente sobreposição das atividades estudadas.

FONTE: do autor (2016).

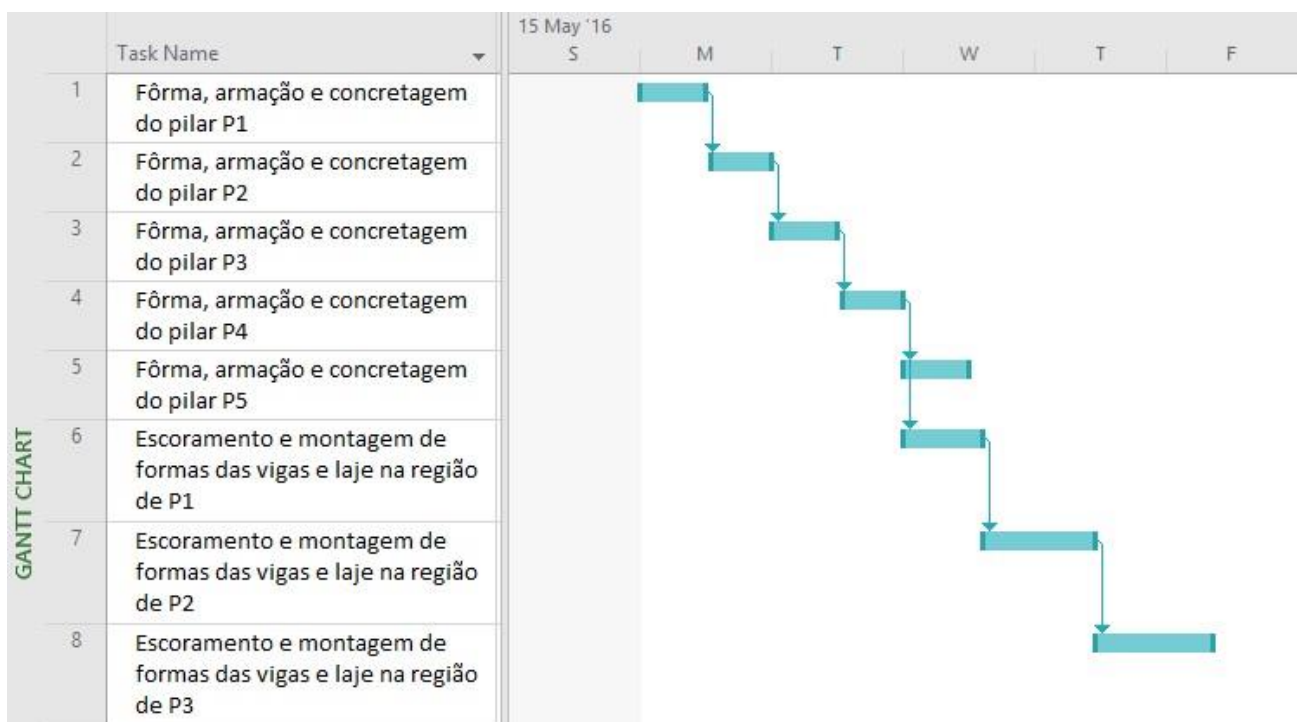

FIGURA 5: Detalhamento do serviço de Execução de Pilares.

FONTE: do autor (2016). 


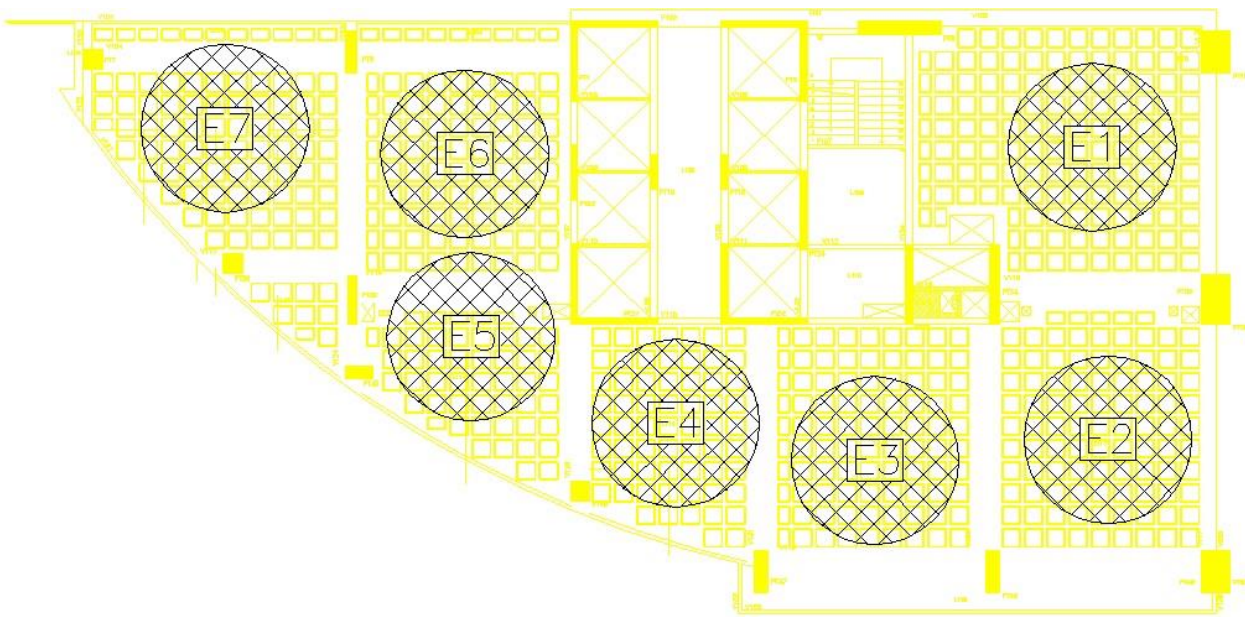

FIGURA 6: Esquematização das equipes em serviço na laje estudada. FONTE: do autor (2016).

Para ilustrar a explicação, na Figura 6 há o projeto estrutural da junta $A$, do pavimento analisado, e sete círculos esquematizados, com diâmetro de 6 metros. As cores do projeto foram alteradas para facilitar a visualização. Considerando que dentro de um círculo de 6 metros de diâmetro há uma equipe de 4 pessoas, se percebe que a laje suporta cerca de 28 colaboradores simultaneamente.

Para exemplificar a particularidade, se considera que em certo tempo " $t$ " tirou-se uma foto aérea da laje da junta $A$ do empreendimento em execução. A foto ilustra a equipe E7 finalizando a montagem de cimbramento da laje e vigas do local, enquanto as equipes $E 6$, E5 iniciam a montagem de armação da região, as equipes E4 e E3 estão finalizando a montagem de armação do local, e por fim, as equipes E2 e E1 iniciam a concretagem da mesma. Portanto, os serviços de cimbramento, armação e concretagem de um mesmo pavimento podem acontecer simultaneamente, porém, se a análise ocorrer pontualmente, as atividades são sequenciais. Dessa forma, percebe-se o motivo do conjunto de atividades de estrutura durar 7 dias, enquanto que a soma das durações de cada atividade isoladamente duram 9,5 dias.

\section{RESULTADOS E DISCUSSÕES}

\subsection{CARACTERIZAÇÃO DO EMPREENDIMENTO}

O local escolhido é uma obra em fase de estruturas, localizado em região nobre da cidade de
Goiânia, Goiás. O objeto de estudo foi o conjunto de atividades de estrutura da junta $A$ do vigésimo terceiro pavimento.

O empreendimento mixed use é composto por três torres, destinados a salas comerciais, shopping center, hotel, hospital e centro clínico. A obra se iniciou em março de 2014 e possui previsão de entrega para maio de 2017, com investimento inicial de 500 milhões de reais. A área construída será de $125.000 \mathrm{~m}^{2}$, com 46 pavimentos, 642 salas comerciais, 101 salas clínicas, 296 apartamentos, 55 lojas comerciais, restaurantes, centro de convenções, auditório, heliponto e 1400 vagas de garagem (Figura 7).

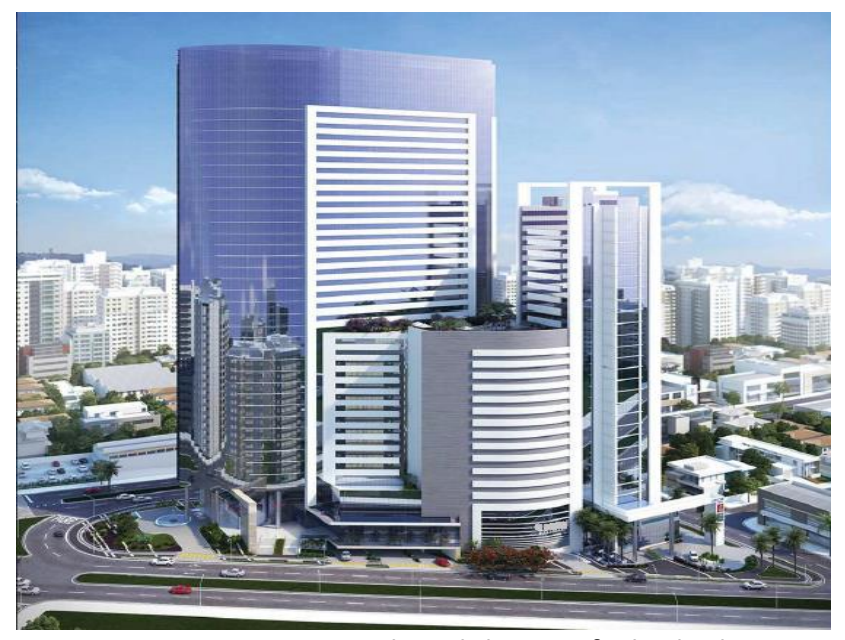

FIGURA 7: Maquete digital de uma fachada do empreendimento finalizado.

FONTE: Fornecido pelo empreendimento (2015).

O empreendimento é gerido por uma Sociedade de Propósito Específica (SPE) formada por quatro pessoas jurídicas e uma física. 
O projeto está sendo executado em concreto armado com destaque para seu sistema de fôrmas e cimbramento inovadores. As fôrmas utilizadas são metálicas, resultando em melhores acabamentos ao concreto e maior ciclo de vida para a fôrma (Figura 8).

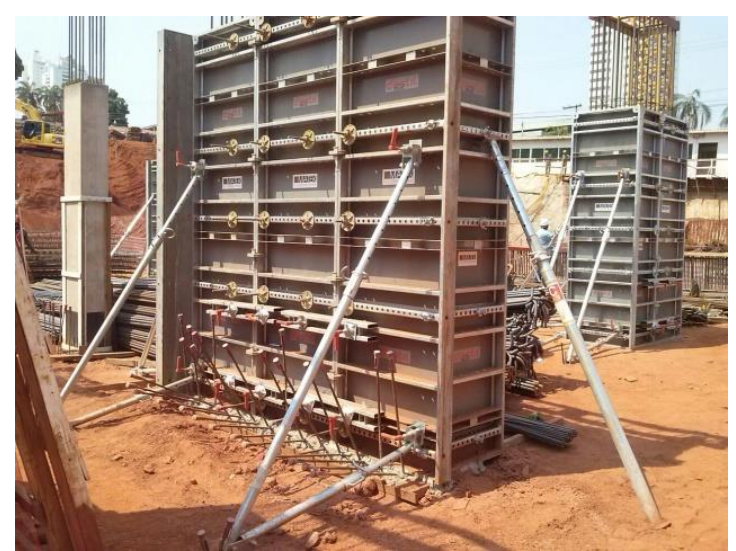

FIGURA 8: Pilar do empreendimento em execução, utilizando fôrmas metálicas.

FONTE: do autor (2015).
O cimbramento da obra em execução utiliza o sistema Drophead e possui um suporte estrutural de vigas e grelhas modulares substituindo as chapas compensadas convencionais, conforme ilustrado na Figura 9.

Esse sistema possui sua execução facilitada, tornando-o mais ágil, além de ser mais seguro e flexível, capaz de se adaptar a obstáculos como pilares e poços de elevador, sem necessidade de cortes e adaptações em obra.

\subsection{MÉTODO DO CINQUENTA POR CENTO}

O método do cinquenta por cento gerou um pulmão de 2,8 dias, resultando numa duração total de projeto de 8,3 dias, ilustrado na Tabela 1.

A partir da Tabela 1, uma ilustração gráfica é feita para auxiliar a observação dos resultados, evidenciada na Figura 10.

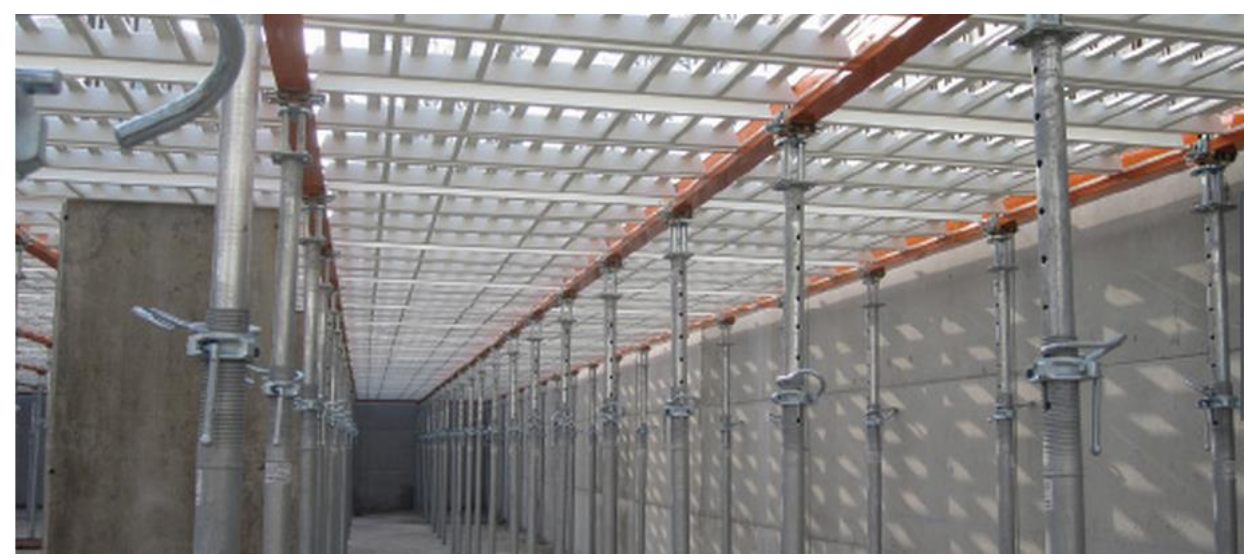

FIGURA 9: Cimbramento, com estruturas de grelhas modulares, utilizando o sistema Drophead. FONTE: www.bmatek.com Acesso em 06/07/16 às 8:03.

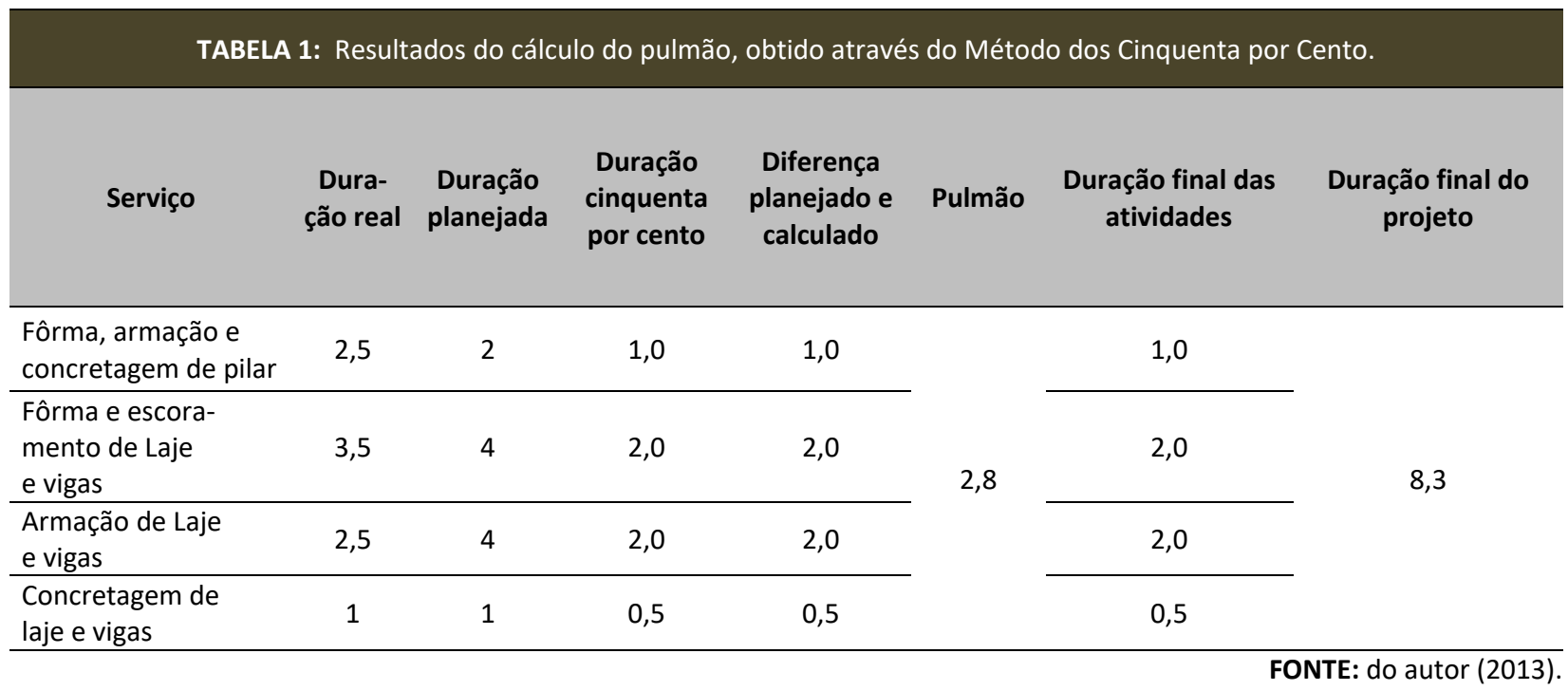




\begin{tabular}{|c|c|c|c|c|c|c|c|c|c|c|c|}
\hline \multirow{3}{*}{$\begin{array}{l}\text { Atividade } \\
\text { Duração } \\
\text { Dia }\end{array}$} & \multicolumn{2}{|c|}{ Pilares } & \multicolumn{4}{|c|}{ Cimbramento vigas e laje } & \multicolumn{4}{|c|}{ Armação vigas e laje } & Concretagem \\
\hline & \multicolumn{2}{|c|}{2 dias } & \multicolumn{4}{|c|}{4 dias } & \multicolumn{4}{|c|}{4 dias } & 1 dia \\
\hline & 1 & 2 & 3 & 4 & 5 & 6 & 7 & 8 & 9 & 10 & 11 \\
\hline Manipulação & 1 dia & 1 dia & \multicolumn{2}{|c|}{2 dias } & \multicolumn{2}{|c|}{2 dias } & \multicolumn{2}{|c|}{2 dias } & \multicolumn{2}{|c|}{2 dias } & 0,5 dia 0,5 dia \\
\hline
\end{tabular}

Após a aplicação do método dos $50 \%$ :

\begin{tabular}{l|c|c|c|c|c|c|} 
Atividade & Pilares & Cimbramento & Armação vigas e laje & Concret. & Pulmão do Projeto & \\
\cline { 2 - 6 } & 1 dia & 2 dias & 2 dias & 0,5 dia & 0,5 dia 1 dia 1 dia & 0,25 dia \\
\hline
\end{tabular}

FIGURA 10: Ilustração gráfica do Método dos Cinquenta por Cento aplicado no estudo de caso. FONTE: do autor (2016).

O método do número Fuzzy trapezoidal gerou um pulmão de 0,5 dia uma duração total do projeto de 9,9 dias conforme ilustrado nas Tabelas 2 e 3 .
Baseando-se nas tabelas de cálculo, cria-se uma ilustração gráfica para melhorar a visualização dos resultados, nas Figuras 11 e 12:

\begin{tabular}{|c|c|c|c|c|c|c|c|c|c|c|c|c|}
\hline \multirow{3}{*}{ Serviço } & \multicolumn{8}{|c|}{ Opinião dos especialistas (tempo) } & \multirow{2}{*}{\multicolumn{4}{|c|}{ Índices }} \\
\hline & \multicolumn{2}{|c|}{ Engenheiro } & \multicolumn{2}{|c|}{ Mestre } & \multicolumn{2}{|c|}{ Carpintaria } & \multicolumn{2}{|c|}{ Armação } & & & & \\
\hline & Otim & Pess & Otim & Pess & Otim & Pess & Otim & Pess & a & b & c & d \\
\hline $\begin{array}{l}\text { Fôrma, armação e } \\
\text { concretagem de pilar }\end{array}$ & 2 & 2,5 & 2 & 2,5 & 2 & 2,5 & 1,5 & 2 & 1,50 & 1,88 & 2,38 & 2,50 \\
\hline $\begin{array}{l}\text { Fôrma e escoramento } \\
\text { de Laje e vigas }\end{array}$ & 3,5 & 3,5 & 3,5 & 3,5 & 3 & 3 & 3 & 3,5 & 3,00 & 3,25 & 3,38 & 3,50 \\
\hline $\begin{array}{c}\text { Armação de Laje } \\
\text { e vigas }\end{array}$ & 2 & 2,5 & 2,5 & 2,5 & 1,5 & 2 & 1,5 & 2 & 1,50 & 1,88 & 2,25 & 2,50 \\
\hline $\begin{array}{c}\text { Concretagem de } \\
\text { laje e vigas }\end{array}$ & 1 & 1 & 1 & 1 & 1 & 1,5 & 1 & 1 & 1,00 & 1,00 & 1,13 & 1,50 \\
\hline
\end{tabular}

FONTE: do autor (2016).

TABELA 3: Continuação dos resultados do cálculo do pulmão, obtido através do Método TrFN.

\begin{tabular}{|c|c|c|c|c|c|c|c|}
\hline \multirow[b]{2}{*}{ Serviço } & \multirow[b]{2}{*}{$\begin{array}{c}\text { Duração } \\
\text { real }\end{array}$} & \multicolumn{2}{|c|}{ Cálculos } & \multirow[b]{2}{*}{$\begin{array}{l}\text { Diferença } \\
\text { th-t* }\end{array}$} & \multirow[b]{2}{*}{ Pulmão } & \multirow[b]{2}{*}{$\begin{array}{l}\text { Duração final } \\
\text { das atividades }\end{array}$} & \multirow{2}{*}{$\begin{array}{l}\text { Duração } \\
\text { final do } \\
\text { projeto }\end{array}$} \\
\hline & & th & $t^{*}$ & & & & \\
\hline $\begin{array}{l}\text { Fôrma, armação e concretagem } \\
\text { de pilar }\end{array}$ & 2,5 & 2,4 & 2,1 & 0,2 & \multirow{4}{*}{0,5} & 2,4 & \multirow{4}{*}{9,9} \\
\hline $\begin{array}{c}\text { Fôrma e escoramento de Laje e } \\
\text { vigas }\end{array}$ & 3,5 & 3,4 & 3,3 & 0,1 & & 3,4 & \\
\hline Armação de Laje e vigas & 2,5 & 2,3 & 2,1 & 0,3 & & 2,3 & \\
\hline Concretagem de laje e vigas & 1 & 1,3 & 1,1 & 0,3 & & 1,3 & \\
\hline
\end{tabular}




\begin{tabular}{|c|c|c|c|c|}
\hline Atividade & Pilares & Cimbramento vigas e laje & Armação vigas e laje & Concretagen \\
\hline Duração Planejada & 2 dias & 4 dias & 4 dias & 1 dia \\
\hline Manipulação & 2,4 dias & 3,4 dias & 2,3 dias & 1,3 dias \\
\hline
\end{tabular}

FIGURA 11: Ilustração gráfica do Método TrFN aplicado ao estudo de caso. FONTE: do autor (2016).

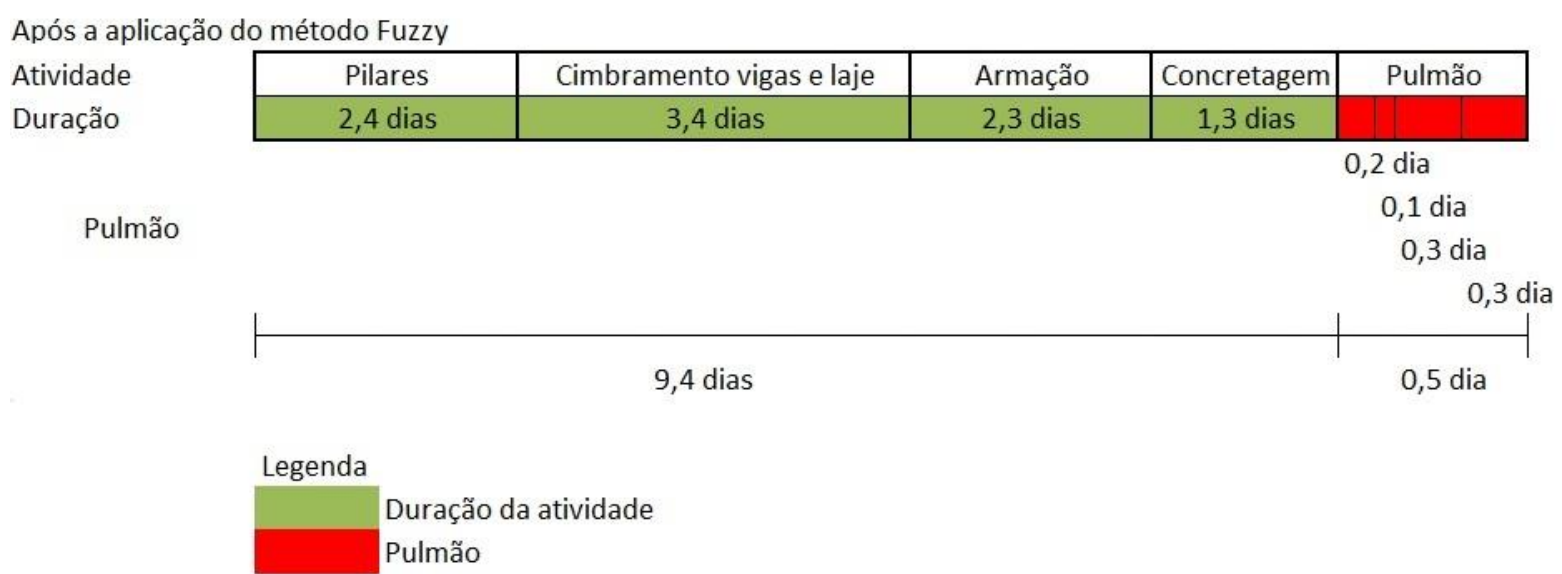

FIGURA 12: Continuação da ilustração gráfica do Método TrFN aplicado ao estudo de caso.

FONTE: do autor (2016).

O pulmão gerado pelo método do número Fuzzy trapezoidal é de 0,5 dia, dentro do prazo de 9,4 dias Fuzzy, sendo pequeno em relação ao método cinquenta por cento em função da baixa incerteza dos especialistas. Enquanto que pelo Método dos Cinquenta por Cento, o pulmão de 2,8 dias é maior, já que a incerteza do projeto era maior antes do início do empreendimento. A Tabela 4 resume os dados através de um comparativo.

Além da quantidade de atividades serem poucas, os especialistas possuem certeza em seus prazos, pois todos eles possuem experiência na área de construção, bem como na obra em execução, considerando que o pavimento analisado é o vigésimo terceiro, e a junta analisada se repete desde o primeiro pavimento. Essa consideração se dá em função do efeito aprendizagem, que através da repetição da tarefa executada, adquire-se experiência, precisão e há o aumento em sua produtividade (HEINECK, 1991).

Analisando a Tabela 4 é possível verificar que o erro entre o Executado e o Método Cinquenta por cento foi de aproximadamente $13 \%$, já a mesma análise com 0 Método TrFN foi de aproximadamente 4\%. Esse resultado corrobora com as conclusões de Quelhas e Barcaui (2005) afirmando que o método cinquenta por cento traz uma redução significativa do tempo do projeto, no entanto o torna mais suscetível a incertezas.

Outro fator que interfere é o fato do produto final da obra ser de alto padrão e também das atividades analisadas estarem no caminho crítico. Dessa forma são feitas cobranças com frequência em todos os níveis hierárquicos para se evitar atrasos nessas atividades e na finalização do empreendimento. Assim, quando se questionou aos especialistas quanto aos possíveis atrasos para coletar o dado "pessimista", com frequência a resposta era "não há atrasos". Dessa forma, além do fato das durações entre os especialistas serem próximas, as opiniões otimistas e pessimistas também se aproximam, resultando num pulmão conciso. Além disso, esse pulmão conciso é justificado pela baixa duração das atividades opinadas pelos especialistas, já que quanto menor a duração da atividade, mais mensurável ela se torna. 
TABELA 4: Comparativo entre as durações planejada, real e calculadas pelos métodos TrFN e 50\% em dias.

Item Planejada Executada $\quad \operatorname{TrFN} \quad \begin{gathered}\text { Diferença } \\ \text { percentual }\end{gathered} \begin{gathered}\text { Cinquenta por } \\ \text { Cento }\end{gathered} \begin{gathered}\text { Diferença } \\ \text { percentual }\end{gathered}$

\begin{tabular}{ccccccc}
\hline Pilares & 2 & 2,5 & 2,4 & $5 \%$ & 1 & $60 \%$ \\
\hline Forma laje e vigas & 4 & 3,5 & 3,4 & $3 \%$ & 2 & $43 \%$ \\
\hline Armação laje e vigas & 4 & 2,5 & 2,3 & $7 \%$ & 2 & $20 \%$ \\
\hline Concretagem laje e vigas & 1 & 1 & 1,3 & $-35 \%$ & 0,5 & $50 \%$ \\
\hline Duração total & $\mathbf{1 1}$ & $\mathbf{9 , 5}$ & $\mathbf{9 , 9}$ & $\mathbf{- 4 \%}$ & $\mathbf{8 , 3}$ & $\mathbf{1 3 \%}$ \\
\hline & & & & & FONTE: do autor (2016).
\end{tabular}

\section{CONSIDERAÇÕES FINAIS}

Após as aplicações dos métodos nos serviços de estrutura do planejamento da obra, se percebe que ambos os cálculos originam pulmões para o monitoramento do seu consumo e evitar possíveis atrasos na finalização do empreendimento. Entretanto, para esse estudo de caso, cada método possui suas particularidades.

O Método TrFN considera a opinião de quatro especialistas para definir os prazos das atividades, e gerar o pulmão do projeto. Isso aumenta a integração da equipe, pois os colaboradores que irão executar o que está no planejamento geram os prazos, criando o sentimento de autoria, aumentando as chances de utilizarem o planejamento inicial e de se esforçarem para seguir o mesmo.

O Método dos Cinquenta por Cento não necessita da opinião dos executores do projeto, o planejador considera os prazos para as atividades, e para gerar o pulmão, há a manipulação das durações definidas. Isso torna esse método mais ágil, resultando na entrega mais rápida do planejamento de longo prazo da obra.

Há também menos desperdício de mão de obra no Método dos Cinquenta por Cento. Por meio do tempo de duração reduzido pela metade, a síndrome do estudante e a lei de Parkinson são evitadas, obtendo um maior aproveitando do insumo, evitando tempos desperdiçados.

Observando a Tabela 4 se nota que as durações calculadas de cada atividade e total pelo Método TrFN são mais próximas ao real e do planejado. O Método dos Cinquenta por Cento define a duração de cada atividade como a metade da duração planejada, havendo nesse estudo de caso uma discrepância do real executado, enquanto que o Método TrFN utiliza dados de quatro especialistas da área, resultando em semelhanças com o real executado. Assim, para esse estudo de caso, o Método TrFN calcula prazos de cada atividade mais próximos ao real.

Pode-se concluir que o Método Cinquenta por Cento, por se tratar de uma redução brusca no tempo das atividades torna o planejamento mais vulnerável, neste estudo, uma diferença de 13\% entre o executado e o Método Cinquenta por Cento para $4 \%$ entre executado e o Método TrFN. Este método considera as incertezas inerentes à construção civil, adaptando o cálculo do pulmão do projeto, enquanto o Método dos Cinquenta por Cento aplica sua redução constante independente das características do projeto.

Entretanto, há a ressalva de que as informações utilizadas para alimentar o Método TrFN foram a partir de especialistas que estão executando o projeto, ou seja, que possuem a experiência e o conhecimento dos detalhes do projeto. Já no Método dos Cinquenta por Cento, utilizou-se dados do planejador, antes do início da execução da obra, não conhecendo a realidade da mesma.

Assim, surge uma proposta para novos estudos: realizar um comparativo dos métodos de cálculo de pulmão TrFN e Cinquenta por Cento em um projeto que ainda não esteja iniciado. Assim, o estudo objetivaria comparar os dados de especialistas não influenciados pelo efeito aprendizagem aplicados no método Fuzzy, e dados do planejador, aplicados no Método dos Cinquenta por Cento. 


\section{REFERÊNICAS BIBLIOGRÁFICAS}

CABRITA, A. F. N. Atrasos na Construção: causas, efeitos e medidas de mitigação. Dissertação (Mestrado em Engenharia Civil) - Universidade Técnica de Lisboa. Instituto Superior Técnico, Lisboa, Portugal, 2008, 161 p.

DE FILIPPI, G. A.; MELHADO, S. B. Um estudo sobre as causas de atrasos de obras de empreendimentos imobiliários na região Metropolitana de São Paulo. Ambiente Construído, Vol. 15 - no 3 - jul./set. 2015 - Porto Alegre, 161-173 p.

GOLDRATT, E. M. Critical Chain. The North River Press. 1997.

HEINECK, L. F. M. Efeito Aprendizagem, Efeito Continuidade e Efeito Concentração no Aumento de Produtividade das Alvenarias. III Simpósio de Desempenho de Materiais de Construção Civil, 1991, Florianópolis. Anais. Florianópolis: Universidade Federal de Santa Catarina. Centro tecnológico, 1991 67-76 p.

LONG L. D. \& OHSATO A. FUZZY CRITICAL CHAIN METHOD FOR PROJECT SCHEDULING UNDER RESOURCE CONSTRAINTS AND UNCERTAINTY Nagaoka University of Technology, International Journal of Project Management 26 (2008) Nagaoka, Japan, 2007, 688-698 p.

PEREIRA, E. S. S. Fatores Associados ao Atraso na Entrega de Edifícios Residenciais. Dissertação (Mestrado em Engenharia Civil). Universidade Federal de Santa Catarina, Florianópolis, 2012, 204 p.

QUELHAS, O; BARCAUI, A.B. A teoria das restrições aplicada à gerência de projetos: uma introdução à corrente crítica. 2005. Disponível em: http://www.pmtech.com.br/newsletter/Marco_2005/T OC_e_CCPM_em_GP.pdf. Acesso em: 04/06/2016 às $13: 22 h$.

RESENDE, V. H. M. PLANEJAMENTO e CONTROLE DE CRONOGRAMA FÍSICO DE OBRAS POR MEIO DA CORRENTE CRÍTICA NO MS PROJECT. Universidade Federal de Goiás - Programa de Pós-Graduação em Geotecnia, Estruturas e Construção Civil, Goiânia, 2015, $246 p$.

SILVA, O.; BRASILEIRO, A.; DUARTE, C. Entrega de apartamentos comprado "na planta": a satisfação do cliente e a reputação da empresa. In: Conferência Internacional da LARES, 11., 2011, São Paulo. Anais... São Paulo: LARES, 2011. Disponível em: < http://lares.org.br/Anais2011/images/571-761-1-

RV.pdf>. Acesso em: 19/5/2016 às 00:52h 